Supplementary Information for ACS Applied Nano Materials

\title{
Polythiophene-Based Carbon Dots for Imaging-Guided Photodynamic Therapy
}

Shaojing Zhao a,\#, Ke Yang a,\#, Lirong Jiang ${ }^{\text {b }}$, Jiafu Xiao ${ }^{c}$, Benhua Wang a, Lintao Zeng b, Xiangzhi Song a, Minhuan Lan a,d,*

${ }^{a}$ Key Laboratory of Hunan Province for Water Environment and Agriculture Product Safety, College of Chemistry and Chemical Engineering, Central South University, Changsha, 410083, P. R. China.

b College of Light Industry and Food Engineering, Guangxi University, Nanning, 530004, P. R. China.

c Hunan Province Key Laboratory for Antibody-based Drug and Intelligent Delivery System, Hunan University of Medicine, Huaihua, 418000, P. R. China.

d Shenzhen Research Institute of Central South University, Shenzhen, 518057, P. R. China.

\# These authors contributed equally to this work.

Corresponding author:

minhuanlan@csu.edu.cn 


\section{Materials and methods}

3-bromothiophene, 4-carboxyphenylboronic acid, pyridine-4-boronic acid, tetrakis(triphenylphosphine)palladium(0), anhydrous $\mathrm{FeCl}_{3}, \mathrm{NaOH}, \mathrm{Na}_{2} \mathrm{CO}_{3}$ were purchased from Alfa Aesar. $\mathrm{CHCl}_{3}$ were distilled from $\mathrm{CaH}_{2}$ under nitrogen.

${ }^{1} \mathrm{H}-\mathrm{NMR}$ and ${ }^{13} \mathrm{C}$-NMR spectra were collected on the Bruker Advance-400 spectrometer with tetramethylsilane (TMS) as an internal standard. Matrix-assisted laser desorption ionization-time-of-flight (MALDI-TOF) mass spectra were obtained on a Bruker Microflex mass spectrometer. Transmission electron microscopy (TEM) and high-resolution TEM (HRTEM) images were acquired by using a JEOL JEM2100F electron microscope. Atomic force microscopy (AFM) images were obtained from Nano-Scope III a MultiMode AFM under tapping mode. X-ray photoelectron spectroscopy (XPS) measurements were carried out on a VG ESCALAB 220i-XL surface analysis system. Fourier transform infrared spectroscopy (FT-IR) was performed on an IFS $66 \mathrm{~V} / \mathrm{S}$ (Bruker) spectrometer. Zeta potential spectrum was recorded on Zeta-size 3000 HS (Malvern, UK). The UV-vis and fluorescence spectra in this work were recorded in Shimadzu UV2600 and RF6000 spectrophotometers, respectively.

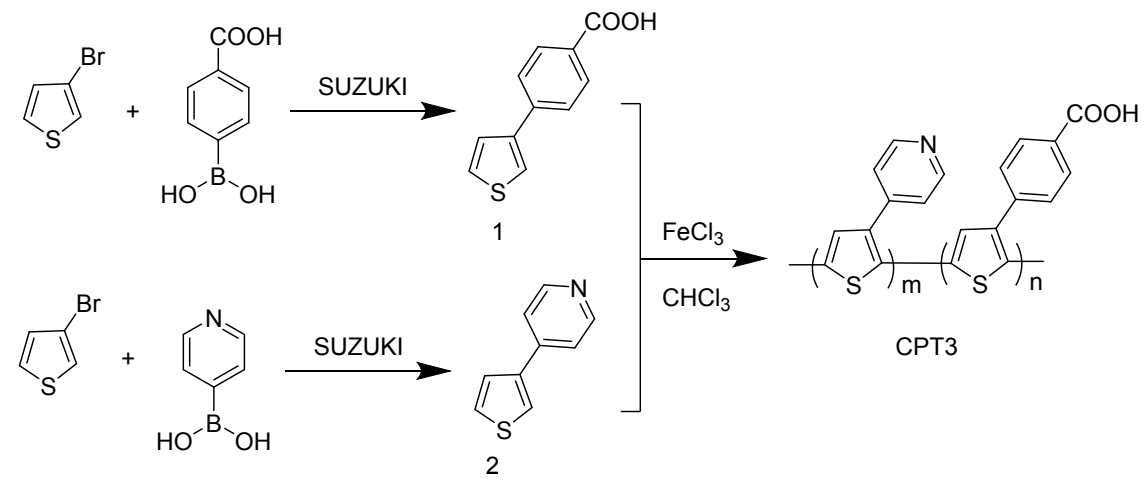

Scheme S1. Synthetic route of CPT3.

\section{Syntheses of 4-(thiophen-3-yl)benzoic acid (Compound 1)}

$10 \mathrm{~mL}$ Deionized water was added with syringes to a mixture of 3-bromothiophene (0.162 g, $1.0 \mathrm{mmol}), \mathrm{Na}_{2} \mathrm{CO}_{3}(0.5 \mathrm{~g}, 4.7 \mathrm{mmol}), \mathrm{Pd}\left(\mathrm{PPh}_{3}\right)_{4}(200 \mathrm{mg}, 0.17 \mathrm{mmol})$, and 4-carboxyphenylboronic acid (0.166 g, $1 \mathrm{mmol})$ in EtOH $(20 \mathrm{~mL})$ under nitrogen. After refluxing at $90^{\circ} \mathrm{C}$ for $9 \mathrm{~h}, \mathrm{EtOH}$ was removed under reduced pressure, and the mixture was neutralized by $1 \mathrm{M} \mathrm{HCl}$. The residue was extracted with $\mathrm{CH}_{2} \mathrm{Cl}_{2}(3 \times 20 \mathrm{~mL})$ and the resulting organic layer was collected and dried with anhydrous $\mathrm{MgSO}_{4}$. After removal of the solvent under reduced pressure, the residue was purified by column 
chromatography (eluent: $\left.\mathrm{CH}_{2} \mathrm{Cl}_{2} / \mathrm{CH}_{3} \mathrm{OH}=6: 1\right)$ to give compound 1 ( 0.15 g, yield $73.5 \%$ ) as a colorless solid. ${ }^{1} \mathrm{H}$ NMR (400 MHz, $\mathrm{CD}_{3} \mathrm{OD}, \mathrm{TMS}, \mathrm{ppm}$, Figure $\left.\mathrm{S} 1\right): \delta$ 7.54-7.55 (d, 2H), $\delta 7.78(\mathrm{~m}, 3 \mathrm{H}), \delta 8.05-8.08(\mathrm{~d}, 2 \mathrm{H}) .{ }^{13} \mathrm{C} \mathrm{NMR}\left(100 \mathrm{MHz}, \mathrm{CD}_{3} \mathrm{OD}\right.$, TMS, ppm, Figure S2): $\delta 121.81,125.79,125.85,130.11,140.23,141.09,168.41 . \mathrm{MS}$ m/z: Calculated: 204.02; Found m/z=204.02 (Figure S3).

\section{Syntheses of 4-(thiophen-3-yl)pyridine (Compound 2)}

The process of preparation and purification of Compound $\mathbf{2}$ is similar with compound 1. ${ }^{1} \mathrm{H}$ NMR (400 MHz, $\mathrm{CDCl}_{3}, \mathrm{TMS}$, ppm, Figure S4): $\delta$ 7.44-7.49 (m, 4H), $\delta 7.67$ (s, $1 \mathrm{H}), \delta 8.61-8.23(\mathrm{~d}, 2 \mathrm{H}) .{ }^{13} \mathrm{C} \mathrm{NMR}\left(100 \mathrm{MHz}, \mathrm{CDCl}_{3}\right.$, TMS, ppm, Figure S5): $\delta 120.96$, 123.22, 125.85, 127.26, 139.67, 142.81, 150.55. MODTOF MS m/z: Calculated: 161.02; Found $\mathrm{m} / \mathrm{z}=161.03$ (Figure $\mathrm{S} 6$ ).

\section{Syntheses of CPT3}

CPT3 was prepared via an oxidative polymerization under nitrogen in the presence of $\mathrm{FeCl}_{3}$. Briefly, $0.1 \mathrm{~g}(0.5 \mathrm{mM})$ compound 1 and $0.048 \mathrm{~g}(0.3 \mathrm{mM})$ compound 2 was dissolved in $20 \mathrm{~mL}$ dry $\mathrm{CHCl}_{3}$ under nitrogen. $0.52 \mathrm{~g}(3.2 \mathrm{mM})$ anhydrous $\mathrm{FeCl}_{3}$ in 10 $\mathrm{mL}$ dry $\mathrm{CHCl}_{3}$ was added into the solution. The reaction mixture was stirred at room temperature for 2 days. The resulting precipitate was collected, washed with methanol, and finally dried under vacuum to give CPT3 as red solid.

\section{Preparation of N,S-CDs}

The N,S-CDs were prepared by hydrothermal treatment of CPT3 in alkaline solution. Briefly, $10 \mathrm{mg}$ of CPT3 were dispersed in $40 \mathrm{~mL}$ of $\mathrm{NaOH}(60 \mathrm{mM})$ aqueous solution. The mixture was ultrasonicated for $1 \mathrm{~h}$ and then transferred into an autoclave (K50, Shanghai LABE Instrument Co., Ltd.) and heated at $200^{\circ} \mathrm{C}$ for a period of $24 \mathrm{~h}$. After cooling to room temperature, the CDs were collected through sequential filtration, centrifugation, and dialysis purification. The CDs were then dispersed in water for further characterization and use.

\section{Fluorescence assay of pH in buffer solutions}

A series of $\mathrm{Na}_{2} \mathrm{HPO}_{4}$-citric acid standard $\mathrm{pH}$ buffer solutions were prepared with adjusted the volume of $\mathrm{Na}_{2} \mathrm{HPO}_{4}$ and citric acid. The $\mathrm{pH}$ values were measured by a Sartorius PB-10 pH-meter. $100 \mu \mathrm{L}(0.4 \mathrm{mg} / \mathrm{mL})$ of CDs stock solution was added into the $1.90 \mathrm{ml}$ buffer solution. The fluorescence spectra of the N,S-CDs in different $\mathrm{pH}$ solutions were recorded and the fluorescence ratios $\left(\mathrm{I}_{500} / \mathrm{I}_{625}\right)$ were calculated from the fluorescence intensities at 500 and $625 \mathrm{~nm}$. 


\section{${ }^{1} \mathrm{O}_{2}$ generation quantum yield Measurements}

The absorbance of CDs and RB was adjusted to $\sim 0.2$ OD. $2 \mathrm{ml}$ sample aqueous solution and $30 \mu \mathrm{L}$ of $\mathrm{Na}_{4}$-ADMA $(1 \mathrm{mg} / \mathrm{mL})$ in a quartz cuvette was illuminated under a Xeon light $(400-800 \mathrm{~nm})$ at room temperature for $6 \mathrm{~min}$. The absorption spectra were recorded at $1 \mathrm{~min}$ intervals. The rate of ${ }^{1} \mathrm{O}_{2}$ generation was determined from the reduced absorbance at $378 \mathrm{~nm}$ over time. The ${ }^{1} \mathrm{O}_{2}$ generation quantum yield $(\Phi)$ was calculated through the following formula:

$$
\Phi_{\mathrm{CDs}}=\Phi_{\mathrm{RB}} \cdot \frac{\mathrm{K}_{\mathrm{CDs}}}{K_{\mathrm{RB}}} \cdot \frac{A_{\mathrm{RB}}}{A_{\mathrm{PS}}}
$$

The ${ }^{1} \mathrm{O}_{2}$ generation quantum yield of the standard reference (RB) is $0.75 . K$ represent the slope of the absorption with the irradiation time. $A$ represent the integral areas of UV-vis absorption spectra ranging from $400-750 \mathrm{~nm}$.

\section{Fluorescence Quantum Yield Test}

Rhodamine B was selected as the standard reference. The relative fluorescence quantum yield of N,S-CDs was calculated according to the following equation:

$$
\varphi_{S}=\varphi_{R} \times \frac{A_{R} \times I_{S}}{A_{S} \times I_{R}} \times\left(\frac{\eta_{S}}{\eta_{R}}\right)^{2}
$$

where the subscripts $R$ and $S$ represent the Rhodamine B and N,S-CDs, respectively, $\varphi$ is the fluorescence quantum yield; $A$ is the absorbance at the excitation wavelength; $I$ is the integral areas of emission spectrum; and $\eta$ is the refractive index of the solvent. The fluorescence quantum yield of N,S-CDs was measured by using Edinburgh FLS 1000 under the excitation of $400 \mathrm{~nm}$.

\section{Cellular Experiments}

The HeLa cells was originally obtained from the American Type Culture Collection (ATCC), and was cultured in a high-glucose Dulbecco's modified Eagle medium (DMEM) at $37^{\circ} \mathrm{C}$ and a $5 \% \mathrm{CO}_{2}$ atmosphere. The in vitro cytotoxicity of CDs was evaluated by MTT assay. HeLa was seeded in 96-well plates at $10^{4}$ well $^{-1}$ and incubated for $24 \mathrm{~h}$. Then, N,S-CDs solution at different concentrations (0, 25, 50, 100 and 200 $\mu \mathrm{g} / \mathrm{mL}$ ) was added into $96-$ well plates and incubated for $24 \mathrm{~h}$. The cell viability was detected by MTT assay following a standard protocol.

\section{Cell imaging}

The HeLa cells were seeded into CLSM culture dishes at an initial cell density of $1 \times$ 
$10^{5}$ cells/well in $2 \mathrm{~mL}$ of DMEM medium. The cells were treated with N,S-CDs with a concentration of $50 \mu \mathrm{g} / \mathrm{mL}$ at $37^{\circ} \mathrm{C}$. After $6 \mathrm{~h}$ incubation, the cell culture medium was removed and cells were washed with PBS $(\mathrm{pH}=7.4)$ for three times before observation by CLSM (Leica TCS SP5, excitation wavelength: $458 \mathrm{~nm}$ laser, signal collection channel: $550 \sim 650 \mathrm{~nm}$ ).

\section{Animal model}

The mice bearing 4T1 tumor model was employed for the in vivo experiments. To construct the model, $3 \times 10^{6} 4 \mathrm{~T} 1$ cells $(100 \mu \mathrm{L})$ were injected into the right flank of the mice via subcutaneous injection (BALB/c, male, 8 weeks). In vivo experiments were conducted when the volume of the 4T1 tumors grew to $\sim 150 \mathrm{~mm}^{3}$. The mice for fluorescence imaging and cancer therapy were purchased from Hunan SJA Laboratory Animal Co., Ltd, and all related animal experiments were performed according to guidelines approved by the ethics committee of Central South University.

\section{In vivo fluorescence imaging}

First, $200 \mu \mathrm{L} \mathrm{CDs}(200 \mu \mathrm{g} / \mathrm{mL})$ aqueous solution was administrated into the mice via the subcutaneous injection. Then, fluorescence imaging was performed after injection of the CDs by using a small animal imaging system IVIS Lumina XR ( $E_{X}: 460 \mathrm{~nm} ; \mathrm{E}_{\mathrm{m}}$ : $670 \mathrm{~nm})$.

\section{In vivo photodynamic cancer therapy}

The 4T1 tumor-bearing mice were randomly divided into four groups and received four different kinds of treatment: PBS, laser, N,S-CDs and N,S-CDs + laser. Mice were kept anesthetized by using $10 \%$ chloral hydrate. Mice that received subcutaneous administration of CDs $(200 \mu \mathrm{g} / \mathrm{mL})$ aqueous solution were subjected to white light for $20 \mathrm{~min}\left(14 \mathrm{~mW} / \mathrm{cm}^{2}\right)$. The body weight and tumor volume of mice from different groups were continually measured for every 2 days. 


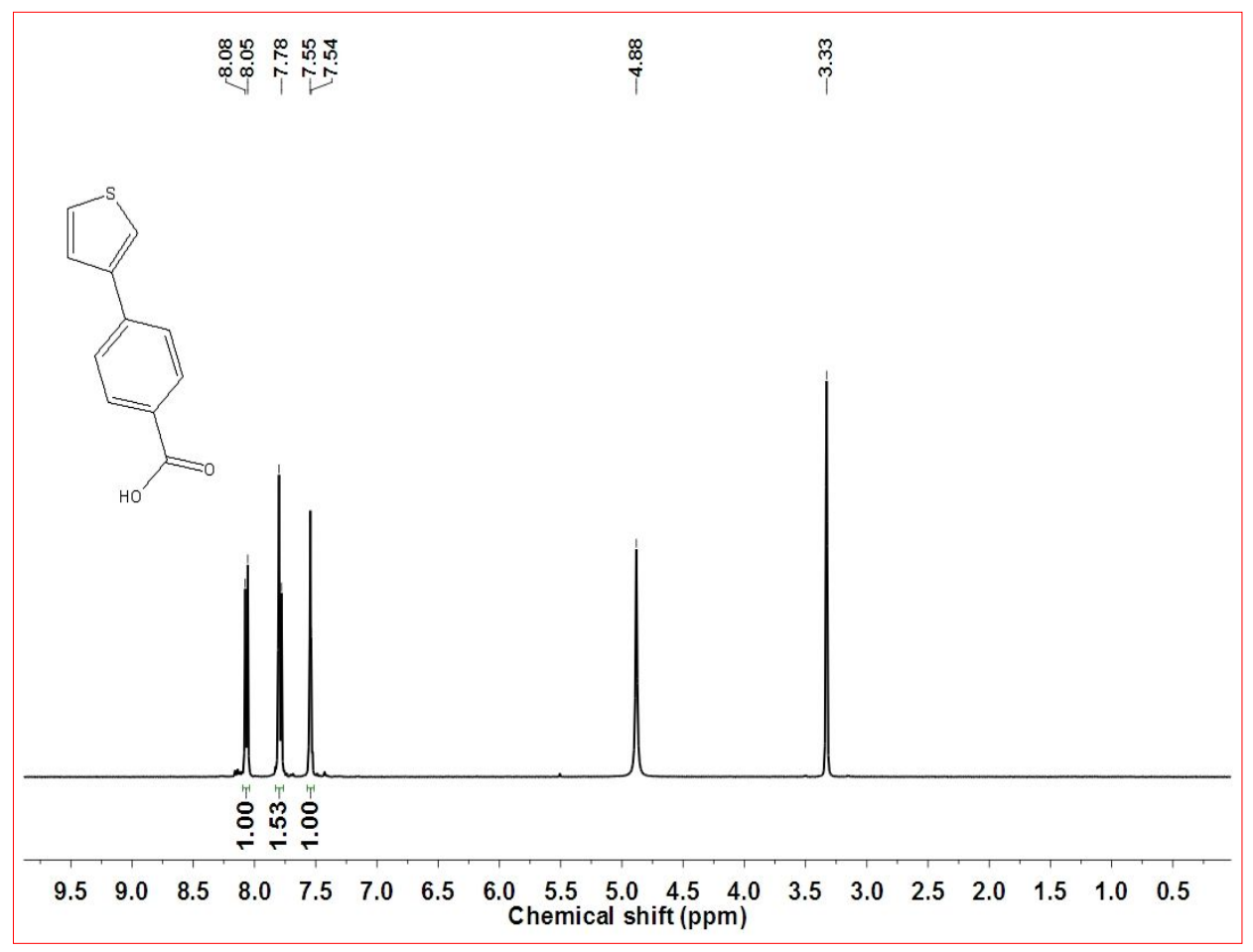

Figure S1. ${ }^{1} \mathrm{H}-\mathrm{NMR}$ spectrum of compound 1 in $\mathrm{CD}_{3} \mathrm{OH}$.

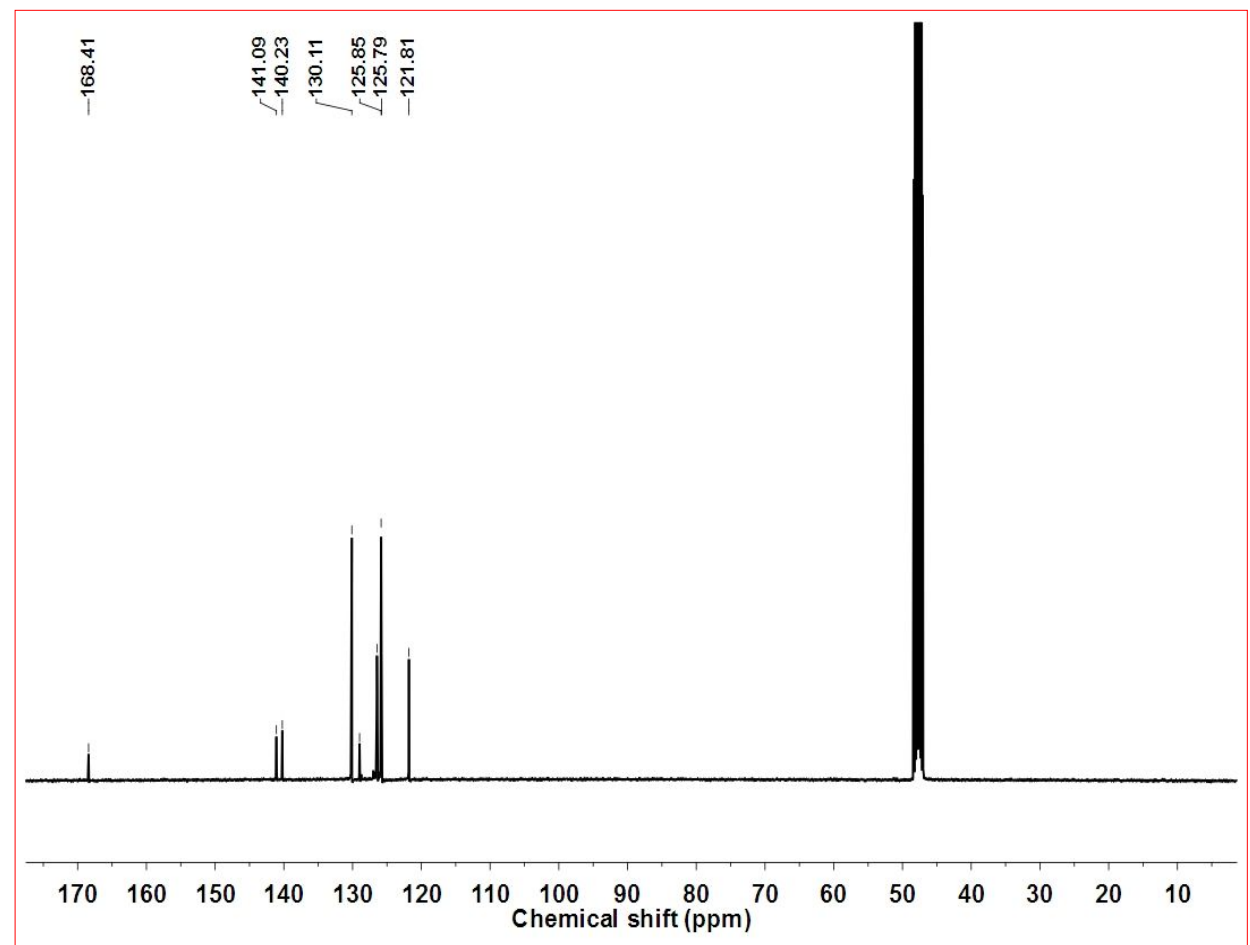

Figure S2. ${ }^{13} \mathrm{C}-\mathrm{NMR}$ spectrum of compound $\mathbf{1}$ in $\mathrm{CD}_{3} \mathrm{OH}$. 


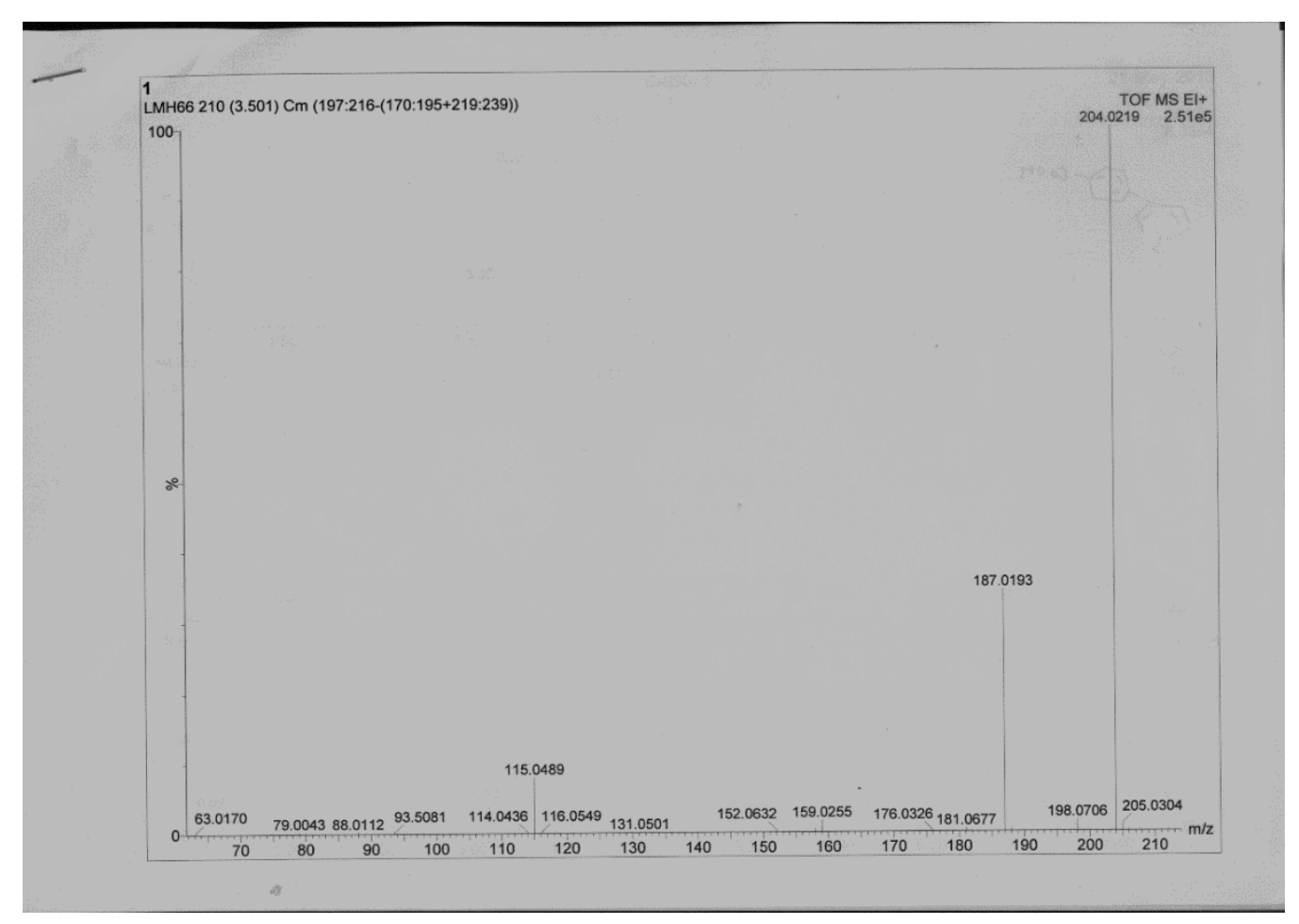

Figure S3. Mass spectrum of compound 1.

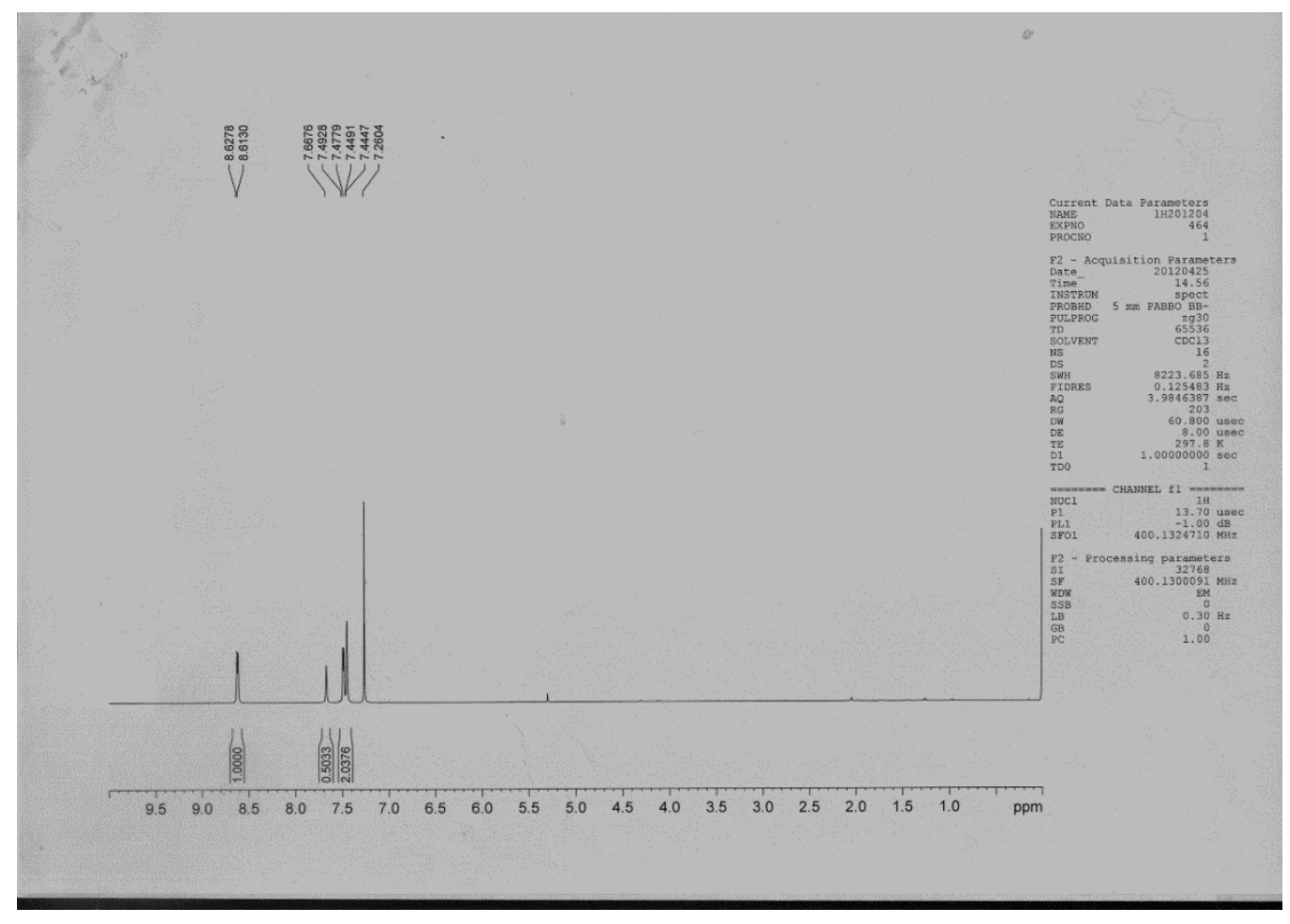

Figure S4. ${ }^{1} \mathrm{H}-\mathrm{NMR}$ spectrum of compound 2 in $\mathrm{CDCl}_{3}$. 


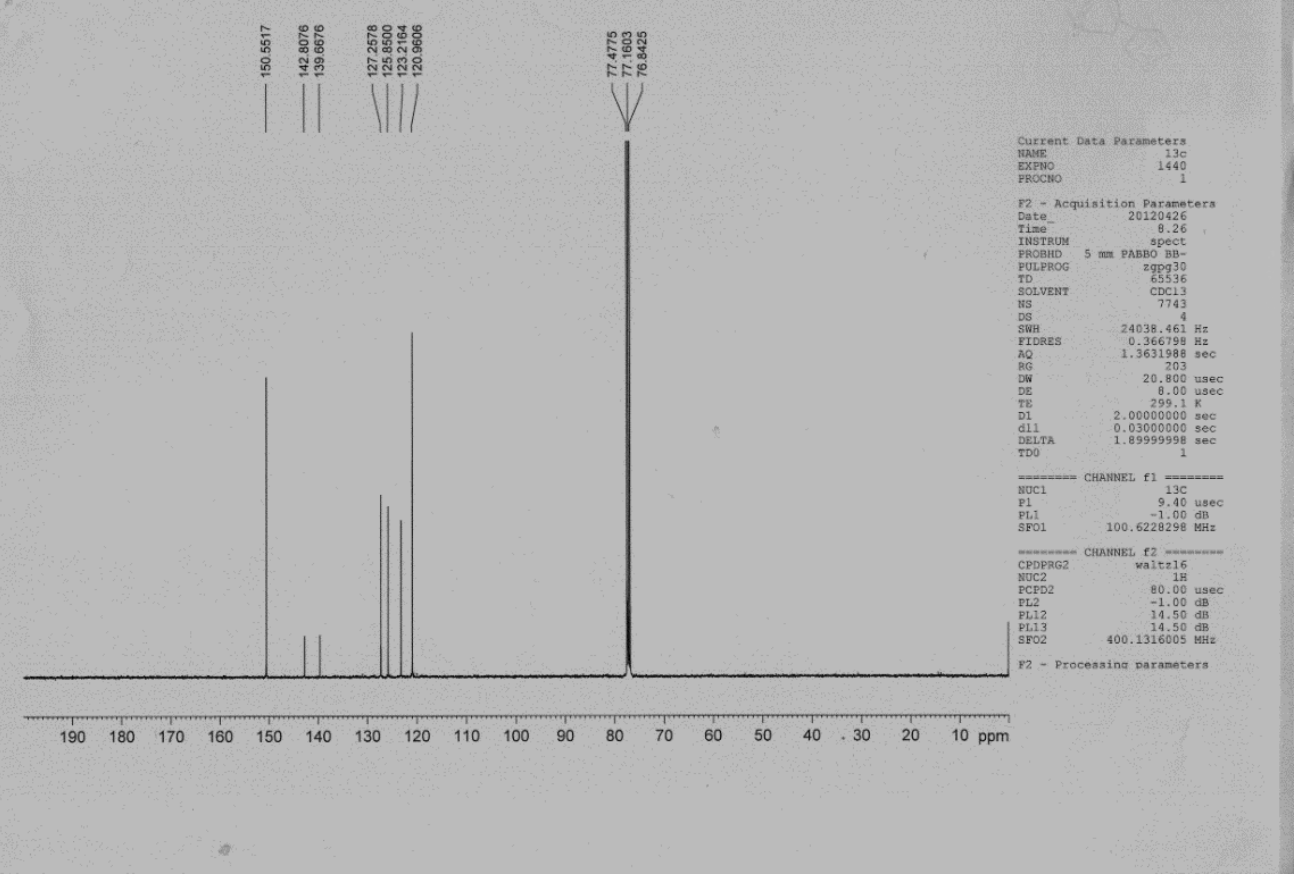

Figure S5. ${ }^{13} \mathrm{C}-\mathrm{NMR}$ spectrum of compound $\mathbf{2}$ in $\mathrm{CDCl}_{3}$.

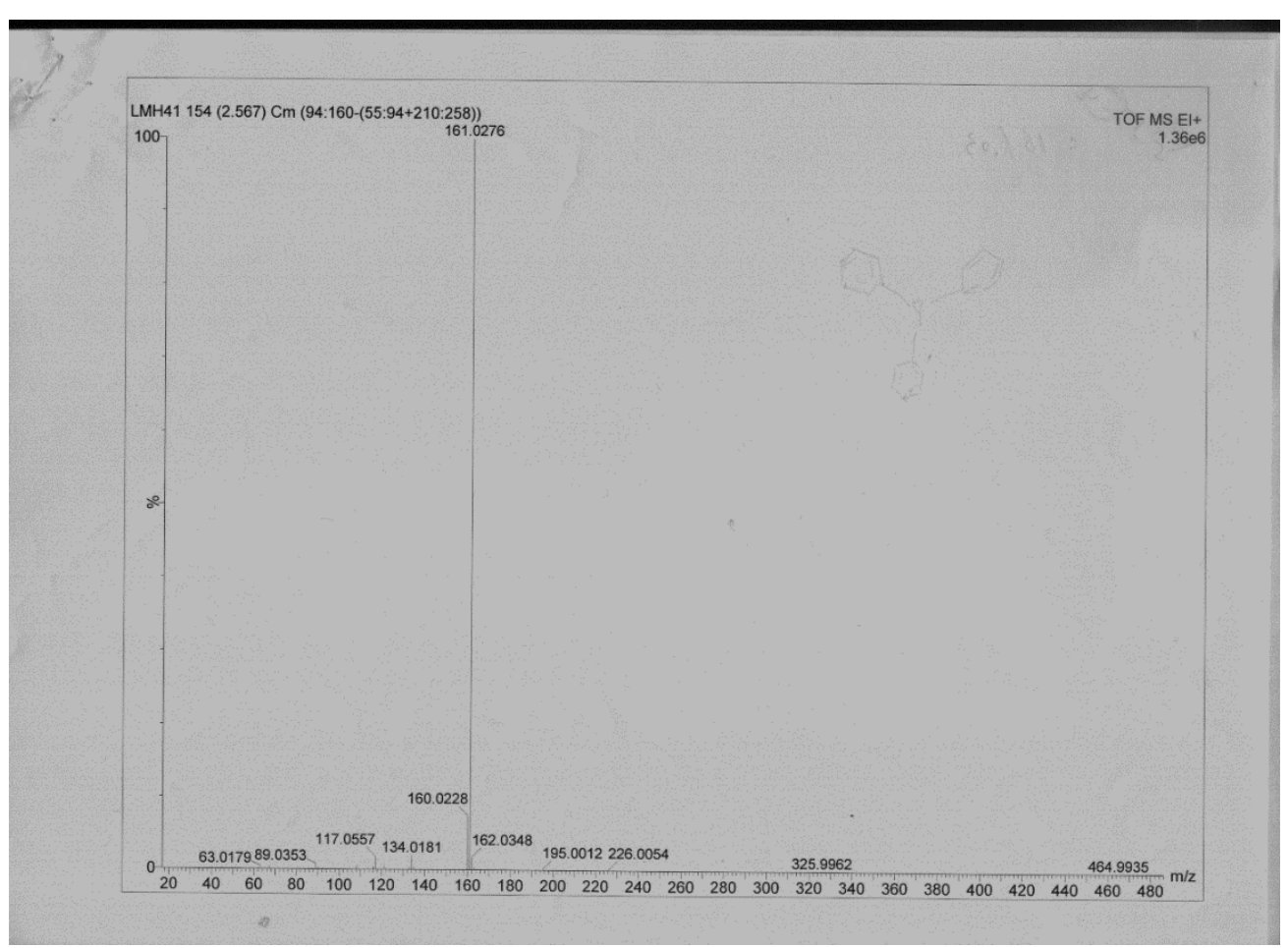

Figure S6. Mass spectrum of compound 2. 


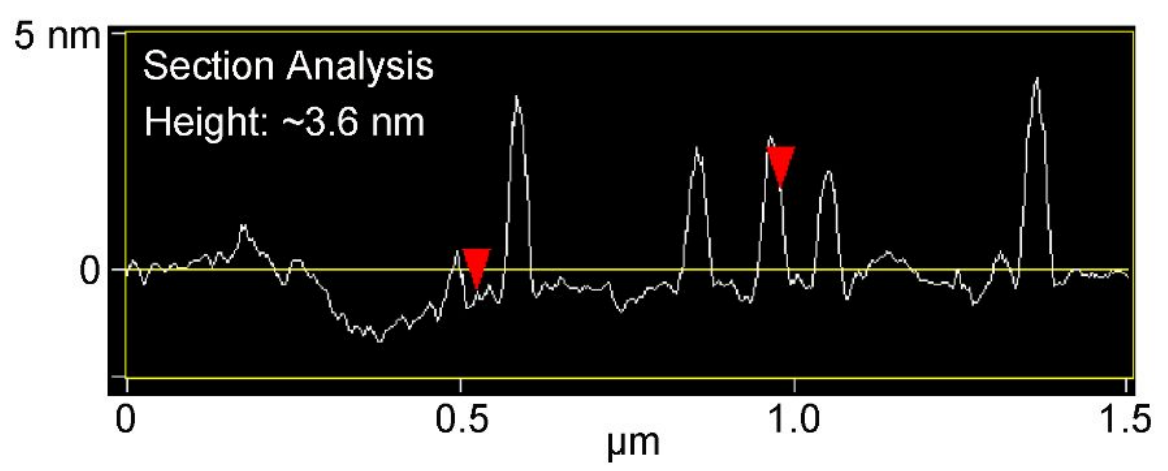

Figure S7. Section analysis of the AFM image.
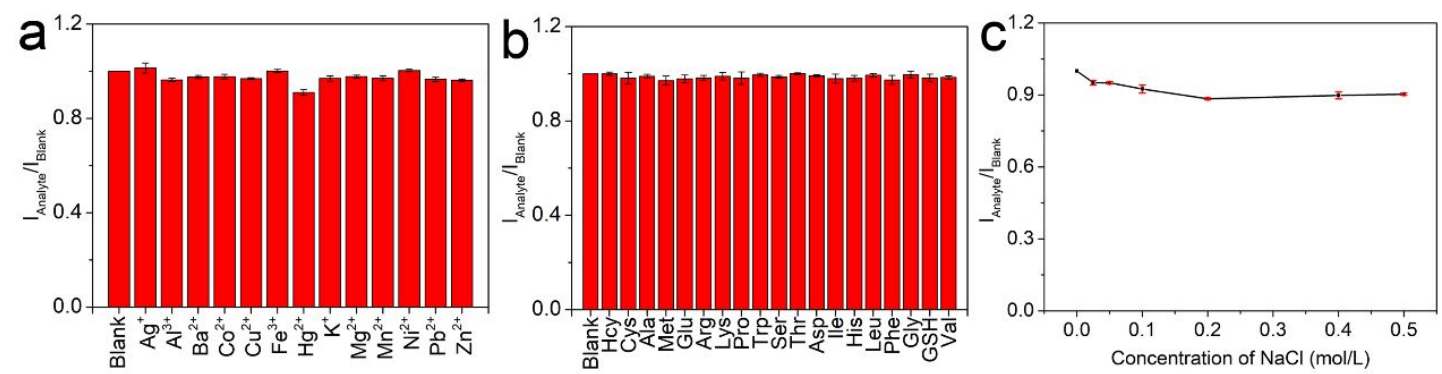

Figure S8. The variation of the fluorescence intensity at $592 \mathrm{~nm}$ of the N,S-CDs in citric acid- $\mathrm{Na}_{2} \mathrm{HPO}_{4}$ buffer solution ( $\mathrm{pH}$ 7.4) upon addition of (a) metal ions (10 $\left.\mu \mathrm{M}\right)$, (b) amino acids $(10 \mu \mathrm{M})$, and (c) $\mathrm{NaCl}$ with concentration from 0 to $0.5 \mathrm{M}$.
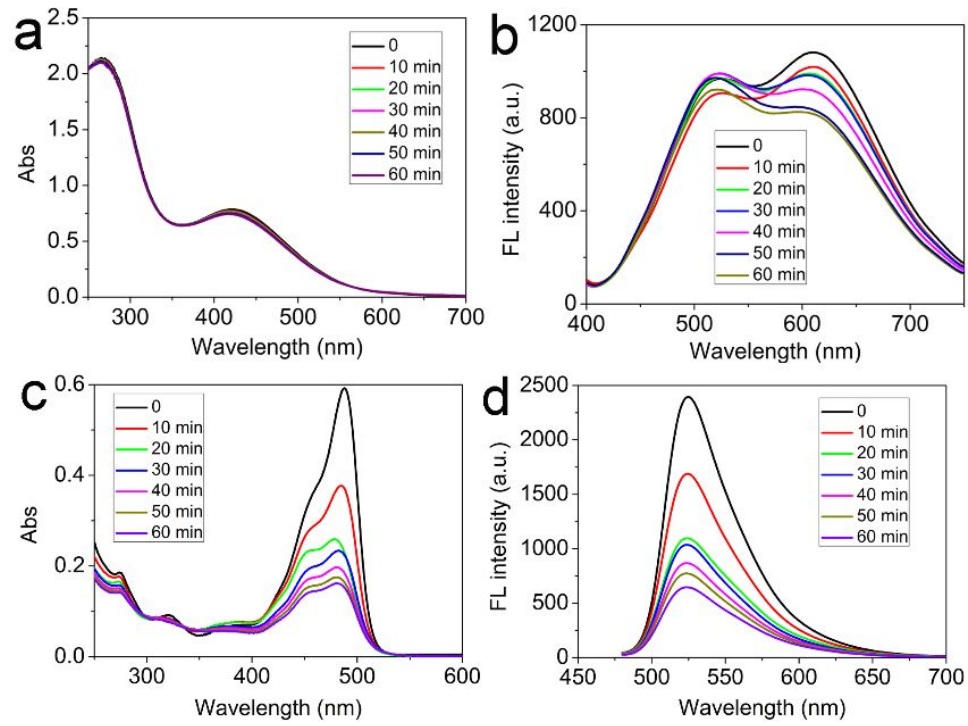

Figure S9. The (a) absorption and (b) fluorescence spectrum of N, S-CDs under the light irradiation. The (c) absorption and (d) fluorescence spectrum of fluorescein sodium under the light irradiation. 


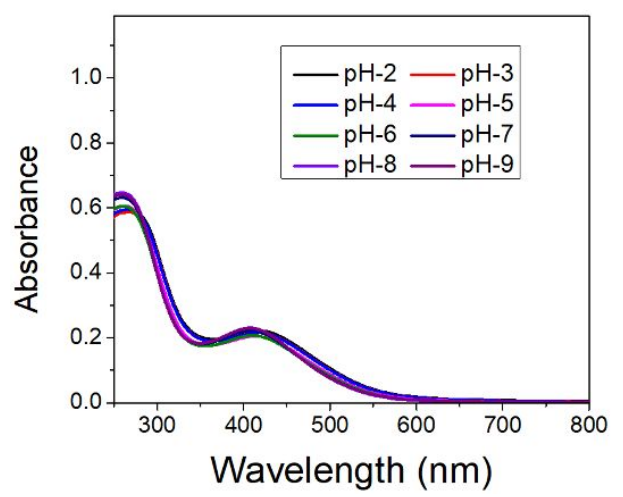

Figure S10. The absorption of N, S-CDs under the different $\mathrm{pH}$ solution.
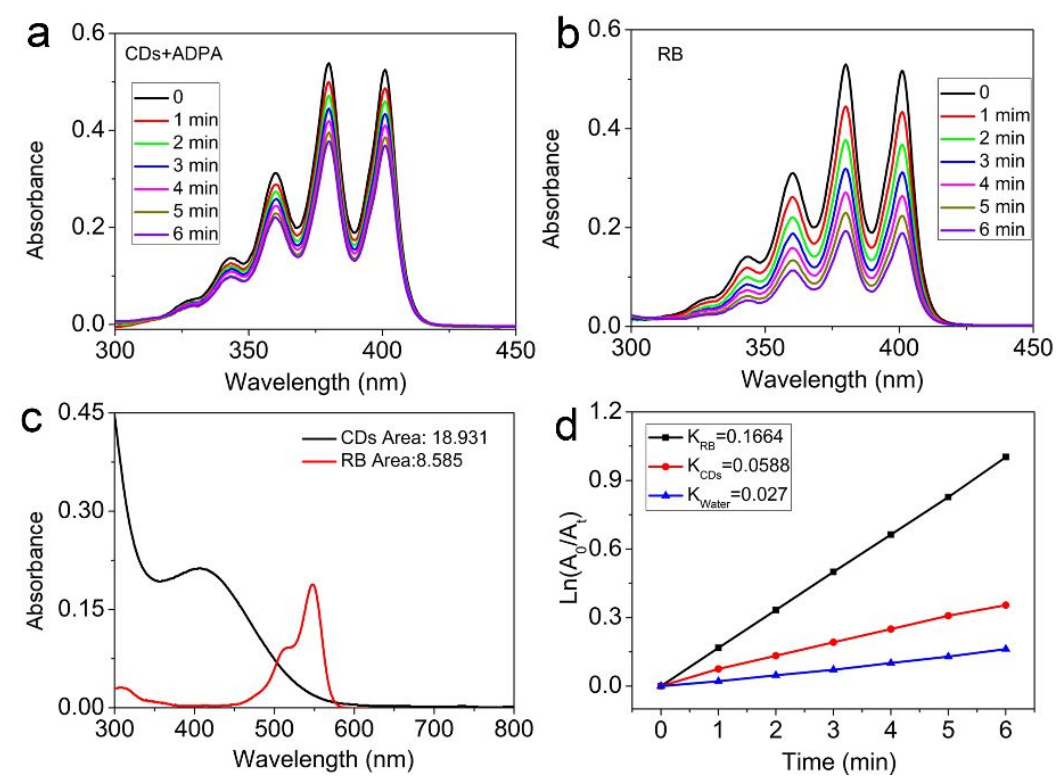

Figure S11. The absorbance of (a) N, S-CDs and (b) RB with the addition of $\mathrm{Na}_{4}-$ ADMA under the light irradiation. (c) UV-vis absorption spectra of N, S-CDs (black line) and RB (red line). The integrated area from $400-780 \mathrm{~nm}$ is 18.931 and 8.585 , respectively. (d) Rate constants for $\mathrm{Na}_{4}$-ADMA decomposition in the presence of CDs and $\mathrm{RB}$, respectively.

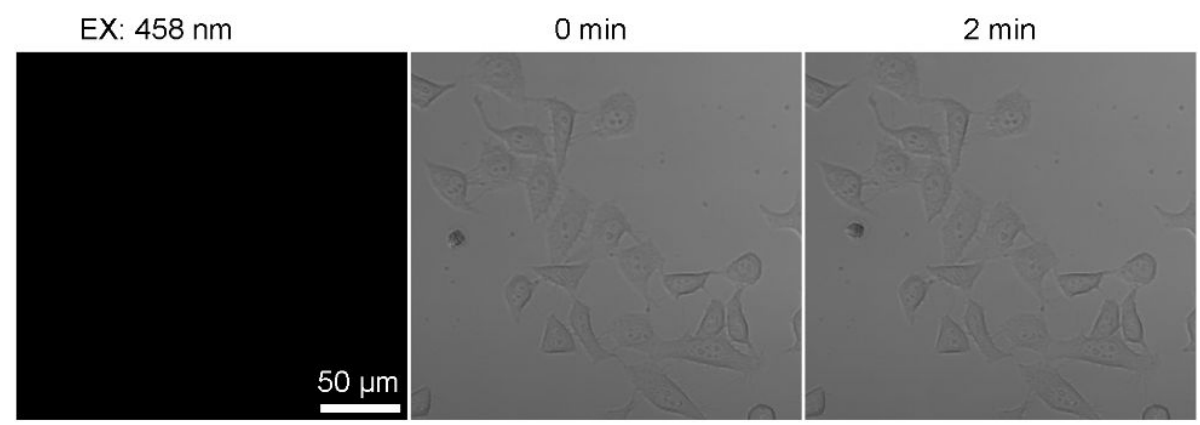

Figure S12. In vitro CLSM images of HeLa cells exposed to laser irradiation for 2 min. 

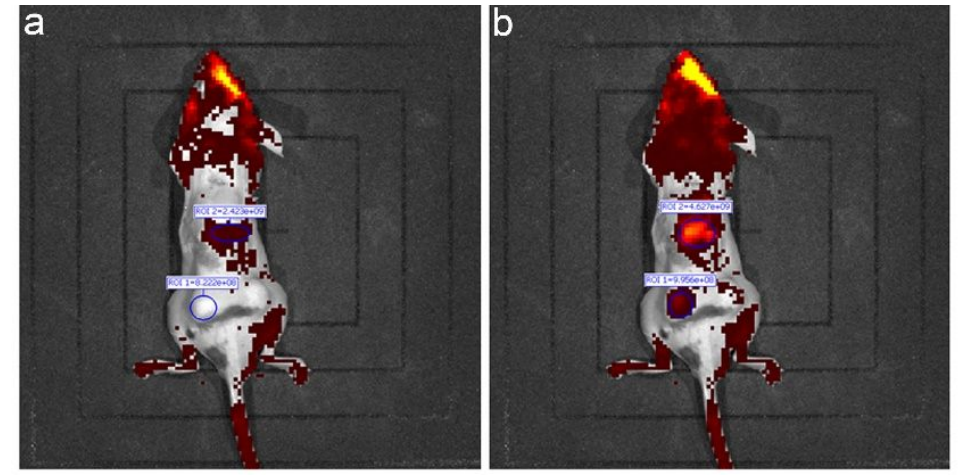

Figure S13. Fluorescence images of a 4T1 tumor-bearing mouse after the injection of CDs in aqueous solution into the tumor and back site, evaluated at the emission wavelength of (a) $520 \mathrm{~nm}$ and (b) $620 \mathrm{~nm}\left(\mathrm{E}_{X}: 420 \mathrm{~nm}\right)$. The upper circle is the back muscle, the lower circle is the tumor. 